\title{
FLUXOS DE NUTRIENTES INORGÂNICOS DISSOLVIDOS EM UM ESTUÁRIO TROPICAL - BARRA DAS JANGADAS - PE, BRASIL.
}

\author{
Carlos DELGADO NORIEGA ${ }^{1}$ \\ Kátia MUNIZ ${ }^{1}$ \\ Moacyr Cunha de ARAÚJO ${ }^{1}$, \\ Rysoaurya Keyla TRAVASSOS ${ }^{1}$ \\ Sigrid NEUMANN-LEITÃO ${ }^{1}$.
}

\author{
${ }^{1}$ Universidade Federal de Pernambuco, Departamento de Oceanografia, Av. \\ Arquitetura s/n Cidade Universitária, Recife. \\ e-mail: carlosnor_ocean@yahoo.com.br/noriega101@hotmail.com
}

Recebido: $15 / 05 / 2005$

Aceito: 31/08/2005

\section{RESUMO}

A previsão dos efeitos antropogênicos requer compreensão dos processos de transporte que geram fluxos. O exemplo de estudo, estuário de Barra de Jangadas-PE, Brasil, sofre uma forte pressão demográfica, recebendo grandes quantidades de resíduos industriais, principalmente provenientes das atividades da cana-de-açúcar e álcool, produtos alimentícios, indústria têxtil, entre outras. O estudo foi desenvolvido durante o inverno de 2003 (Julho) durante um período de sizígia. O objetivo principal deste trabalho foi caracterizar a dinâmica dos câmbios de nutrientes na interface rio-oceano através da quantificação dos fluxos na zona de confluência dos rios no referido estuário, com a finalidade de estimar a importação e exportação diária. Importantes variações foram detectadas ao longo do ciclo temporal estudado. Altos fluxos de amônia $\left(608,00 \mathrm{~kg} . \mathrm{d}^{-1}\right)$ e, silicato $\left(18.480,00 \mathrm{~kg} . \mathrm{d}^{-1}\right)$ evidenciou um aumento nos aportes antropogênicos diretos e indiretos influenciados pelo aumento na descarga fluvial neste período. A relação N:P e Si:P (Redfield) 18:1 e 86:1 respectivamente, evidenciou o fosfato como elemento limitante, sendo corroborado pelas diferenças entre as concentrações do dia e da noite $(\Delta \%=10)$. As altas concentrações dos nutrientes na baixa-mar e enchente são reduzidas paulatinamente quando o estágio de preamar chega a seu estofo, renovando a água, permitindo a degradação oxidativa da matéria orgânica, e dando à zona de mistura estuarina uma maior capacidade de depuração, que é mantida até a chegada do seguinte estágio de maré, onde a influência fluvial novamente se faz sentir. As variações nos fluxos apresentaram seu máximo nos horários de tarde e noite, sendo atribuído à atividade biológica e decomposição da matéria orgânica.

Palabras-chave: fluxos, importação, exportação, interface.

Tropical Oceanography, Recife, v. 33, n. 2, p. 133-145, 2005. 


\title{
FLOW OF INORGANIC NUTRIENTS DISSOLVED IN A TROPICAL ESTUARY - BARRA DAS JANGADAS - PE, BRAZIL.
}

\begin{abstract}
The Barra de Jangadas estuarine system (PE, Brazil), is subjet to strong demographic pression. It receives high waste load mainly from the sugar-cane and alcohol, food, and textile industries, among others. To foreseen the anthropogenic effects in this system it is necessary to understand the transport processing that make the different fluxes. This work intented to characterize the changes in nutrients dynamic in the river-ocean interface by quantifying the fluxes at the confluence zone of the Pirapama and Jaboatão rivers, wich form this estuary. The study was developed to access the daily import, and export of dissolved nutrients in the rainy season (July/2003). High variations were observed during the temporal cycle. High ammonia fluxes $\left(608.00 \mathrm{~kg} \cdot \mathrm{d}^{-1}\right)$ and silicate $\left(18,480.00 \mathrm{~kg} \cdot \mathrm{d}^{-1}\right)$ showed an increase in the anthropogenic impacts caused by higher rivers discharge during this season. The relation N:P and Si:P (Redfield) 18:1 and $86: 1$ respectively, showed that phosphate can be limiting, contributing to the diurnal and nocturnal concentrations differences $(\Delta \%=10)$. The high nutrient concentration during ebb and low tides are slowly reduced during the maximum high tide, renewing the water and oxygenating the system. This process gives to the zone of estuarine mix a higher depuration capacity which is maintained until the next tide stage, when the system is again under the river influence. The fluxes variations presented their maximum during the sundown and night, being attributed to the biological activity and the organic matter decomposition.
\end{abstract}

Key-words: fluxes, importation, exportation, interface.

\section{INTRODUÇÃO}

Os estuários estão inseridos numa interface dinâmica entre o continente e o oceano, cuja complexidade dos processos hidrodinâmicos está relacionada com fatores como a batimetria local, o input de água doce e as oscilações de maré. Nas zonas estuarinas os nutrientes em geral são originados dos rios, normalmente numa relação inversa entre a concentração desses elementos e a salinidade.

A previsão dos efeitos antrópicos requer a compreensão dos processos de transporte que geram fluxos. A quantificação desses fluxos em um estuário inclui algumas dificuldades, entre elas se destacam:

- A variabilidade da descarga dos rios; de acordo com o padrão anual de chuvas, o rio tem comportamentos sazonais.

- As relações entre as concentrações e o fluxo; as concentrações são de certa forma uma função do rio e também da estação do ano.

- Os processos estuarinos; os nutrientes $(\mathrm{N}, \mathrm{P}, \mathrm{Si})$ que chegam aos estuários através dos rios, estão sujeitos a processos biológicos e químicos, como resultado, a carga que entra no estuário não é igual à que chega à zona costeira.

- A variabilidade das marés.

O estuário da Barra das Jangadas, drena uma bacia hidrográfica com cerca de $1000 \mathrm{~km}^{2}$, e se localiza no município de Jaboatão dos Guararapes-PE $(20 \mathrm{~km}$ ao sul da cidade do Recife Brasil). Sendo formado pela confluência dos rios Pirapama e Jaboatão, sofre forte pressão demográfica, recebendo ainda expressiva quantidade de resíduos industriais, sobretudo provenientes

Tropical Oceanography, Recife, v. 33, n. 2, p. 133-145, 2005. 
de atividades sucro-alcooleira, produtos alimentares, texteis, entre outras (www.cprh.pe.gov.br). As marés são de tipo semidiurno, com variações médias de altura de $1 \mathrm{~m}$ nos períodos de quadratura, e $2 \mathrm{~m}$, nos períodos de sizígia (Falcão, 2002). O estuário apresenta-se como um sistema bem misturado tipo 1, segundo a tipologia de Hansen; Rattray (1966), (Noriega, 2004). A Barra das Jangadas, assim como todo litoral pernambucano, possui clima tropical quente e úmido do tipo As', com chuvas de outono-inverno segundo a terminologia de Köppen, caracteriza-se por apresentar temperatura anual elevada de aproximadamente $25,5^{\circ} \mathrm{C}$ e precipitação anual superior a $2000 \mathrm{~mm}$ em duas estações distintas: a seca determinada pela evaporação superior à precipitação e a chuvosa onde a evaporação é inferior à precipitação (Carneiro; Coelho, 1960).

Segundo Souza; Tundisi (2003) estudando o rio Jaboatão, e Falcão (2002), o Pirapama, a época mais crítica em relação à qualidade dos dois rios foi durante o inverno, onde o incremento das vazões desses rios devido às chuvas, provocaram uma deterioração da qualidade da água na zona estuarina.

O objetivo principal deste trabalho foi caracterizar a dinâmica da troca de nutrientes na interface rio-oceano, através da importação e exportação no estuário da Barra das Jangadas e quantificar os nutrientes que estariam provocando a degradação da qualidade da água.

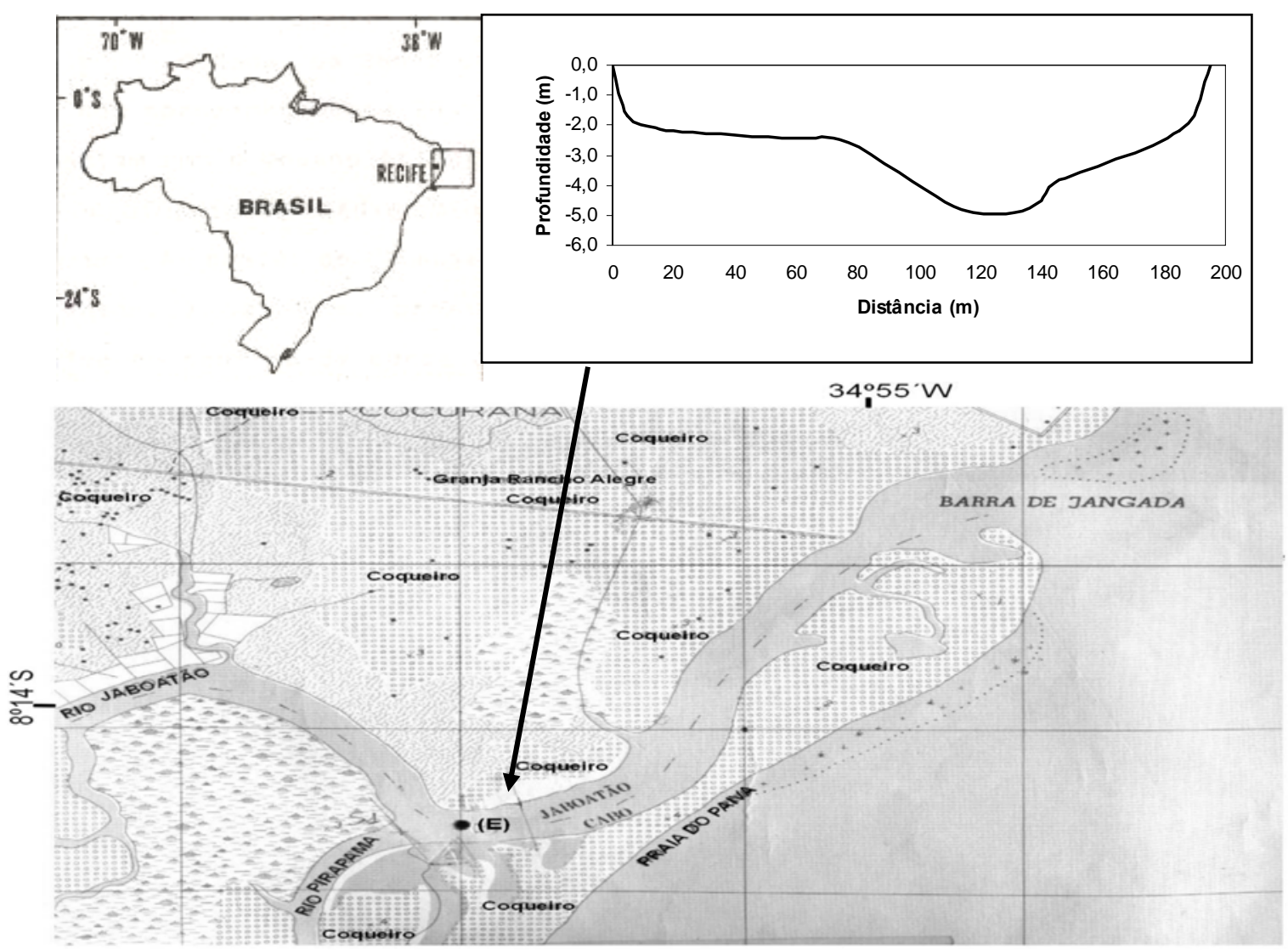

Figura 1 - Mapa da área de estudo indicando a localização do ponto de amostragem $(\bullet)$ na confluência dos rios.

Tropical Oceanography, Recife, v. 33, n. 2, p. 133-145, 2005. 


\section{MATERIAL E MÉTODOS}

A metodologia seguida para alcançar os objetivos propostos, foi o monitoramento durante 24 horas durante a época invernal (29 e 30 de julho de 2003) em uma maré de sizígia (intervalo horário) em uma seção transversal da zona de confluência dos rios Pirapama e Jaboatão. Através de uma embarcação motorizada, foram realizadas medições simultâneas da magnitude e direção das correntes de maré, através de um correntometro Sensordata SD-30, e dos perfis verticais de Temperatura, Salinidade e profundidade através de um perfilador CTD Seabird SBE-19. Nessa secção, foi estabelecido um total de três estações de coleta (Ilha, Centro e Continente) (Fig 1), cujas posições foram georeferenciadas com o auxilio de um GPS Garmin 12. Simultaneamente foram coletadas amostras de água para a determinação das concentrações de nutrientes $\left(\mathrm{N}^{-} \mathrm{NO}_{2}{ }^{-} ; \mathrm{N}-\mathrm{NO}_{3}{ }^{-}\right.$; $\mathrm{N}-\mathrm{NH}_{4}{ }^{+}+\mathrm{NH}_{3} ; \mathrm{PO}_{4}{ }^{3-} ; \mathrm{SiO}_{2}$ ), através das técnicas de Grasshoff et al. (1983).

Para a determinação do fluxo dos nutrientes, foi utilizado os dados obtidos de velocidade para cada estação nas distintas profundidades, os vetores de velocidade de corrente foram decompostos nas componentes $u$ (longitudinal ao canal) e $v$ (transversal ao canal), utilizando-se a relação apresentada em Miranda et al. (2002). O transporte líquido ao longo dos ciclos de marés, foi calculado de acordo com Pereira-Filho et al. (2001), através de integração no tempo, quando a propriedade integrada é expressada em unidades de massa $(\mathrm{kg})$, e pode ser representada através da expressão da figura 2 :

$$
\Phi=A_{t} \int_{t 1}^{t 2}\langle\overline{c u}\rangle d t
$$

Figura 2 - Equação para a determinação dos fluxos em uma seção transversal.

onde, $A_{t}$ é a área instantânea da seção transversal $\left(\mathrm{m}^{2}\right), \bar{C}$ é a concentração do parâmetro $\left(\mathrm{kg} \cdot \mathrm{m}^{-3}\right)$, e $\bar{u}$ é a velocidade da corrente $\left(\mathrm{m} \mathrm{s}^{-1}\right)$. A barra representa a média na seção transversal, e os colchetes $<>$ a média no tempo. O transporte líquido foi calculado efetuando médias no tempo de cada propriedade. Os valores médios positivos indicam o transporte para fora do estuário, e valores negativos, transporte para dentro do estuário.

Inicialmente, uma régua graduada foi fixada em uma das colunas do píer da Marina Acquamarine, com o objetivo de monitorar as variações do nível d'água durante o período de coleta. Foram realizadas leituras da régua e registrado os valores a cada quinze minutos. A sondagem batimétrica permitiu localizar os perfis transversais de cada uma das estações de coleta. Para diferentes valores de Y (distância transversal a partir da margem direita do estuário), a correspondente profundidade foi anotada enquanto se fazia o percurso da margem de referência à margem oposta. Dessa forma, o leito do canal foi discretizado em cada estação, permitindo o cálculo da área de cada seção transversal (A), o que foi feito através do método dos trapézios.

Visando ainda investigar o comportamento das marés dentro do estuário da Barra das Jangadas, foram obtidos os registros do nível das águas in situ e comparados aos registros das previsões das marés para o Porto do Recife (www.dhn.mar.mil.br) 


\section{RESULTADOS E DISCUSSÃO}

\subsection{Variáveis Físicas.}

A área da seção transversal estudada mostrou variações de acordo com as oscilações da maré, com um máximo de $616,00 \mathrm{~m}^{2}$ e um mínimo de $530,00 \mathrm{~m}^{2}$. As marés no estuário da Barra das Jangadas apresentaram uma variação de nível entre baixa-mar e preamar mais alta que as marés no Porto do Recife. Durante a maré de sizígia amostrada, a altura das marés no Porto do Recife foi de 2,00 e 2,10m, enquanto que na Barra das Jangadas foi de 2,09 e 2,20m (Tab. 1). As preamares, para o período estudado, estão em fase com as marés do Porto do Recife (Tab. 1; Fig 3). As baixa-mares na Barra das Jangadas ocorrem de 42 a 47 minutos após a ocorrência da baixa-mar no Porto do Recife durante a maré de sizígia.

Maré de Siźgia (29-30/07/2003)

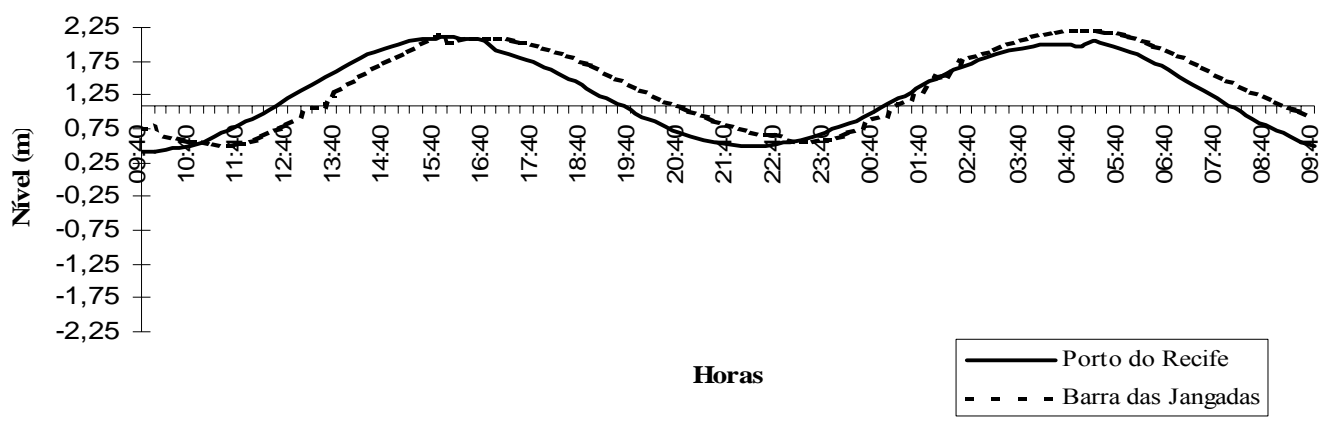

Figura 3 - Curva de marés no Porto do Recife e no ponto de coleta no estuário de Barra das Jangadas (Julho, 2003).

Segundo Lins (2002), as marés na costa resultam da propagação das marés oceânicas. A forma da linha de costa, presença de baías, estuários, ilhas, etc., modificam bastante o sinal das marés, influenciando sua altura e características, podendo resultar tanto na ampliação do sinal das marés por ressonância e reflexão, como na sua redução, pela dissipação da energia pelo atrito de borda e de fundo. No estuário da Barra das Jangadas, as baixas profundidades, acidentes orográficos (banco de areia perto da margem lateral esquerda na boca do estuário) e a altura sobre o nível do mar são fatores que influenciam a energia das marés e modificam a simetria de sua curva (desigualdade semi-diurna).

A propagação da maré se deu na forma de uma onda mista, ocorrendo uma defasagem entre a máxima velocidade de enchente (valores negativos de $\mathrm{u}$ ) e o máximo nível de água de $3,10 \mathrm{~h}$ e, entre a máxima velocidade de vazante (valores positivos de u) e o mínimo nível de água de 3,55 h (Fig 3 e 4). 


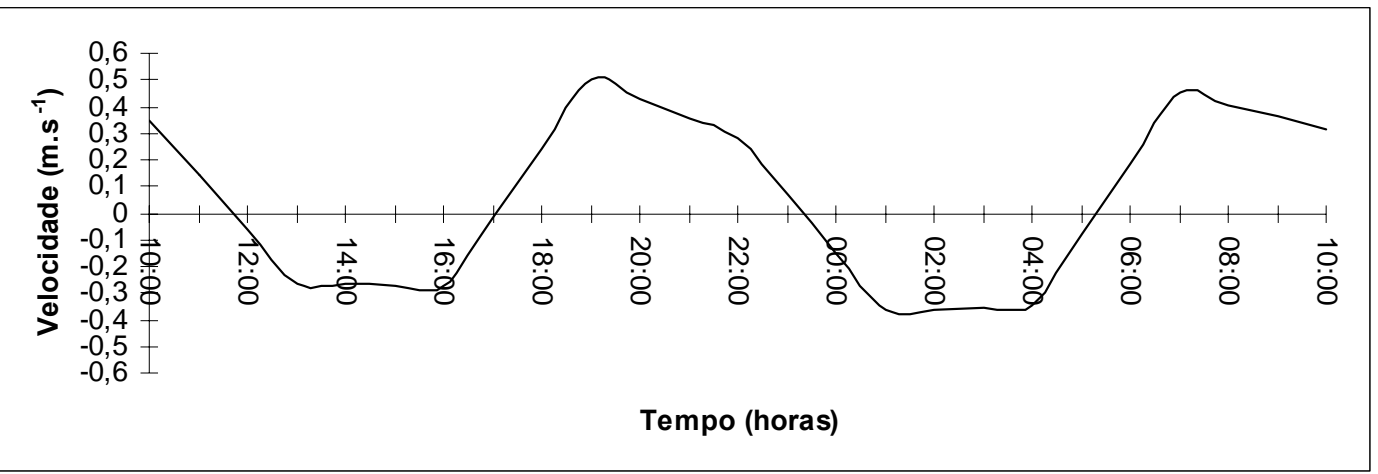

Figura 4 - Variação das velocidades médias durante o período estudado no estuário de Barra das Jangadas.

As velocidades na secção apresentaram um pico máximo de $0,504 \mathrm{~m} \cdot \mathrm{s}^{-1}$ durante o estágio de vazante, e um mínimo de $0,06 \mathrm{~m} \cdot \mathrm{s}^{-1}$ durante o estofo de baixa-mar. A velocidade média foi de $0,274 \mathrm{~m} \cdot \mathrm{s}^{-1}$, com uma velocidade residual de $0,040 \mathrm{~m} \cdot \mathrm{s}^{-1}$ no sentido continente-oceano, evidenciando a característica exportadora do sistema (estuário positivo).

A variação temporal dos parâmetros foi fortemente condicionada pela maré, verificando-se uma assimetria nas correntes de maré, com duração de 4,00 h para vazante e $6,30 \mathrm{~h}$ para enchente, em função de sua interação com os contornos do canal (Fig 4).

Os máximos valores de salinidade ocorreram com um quarto de período de diferença com os máximos valores de velocidade, comum para estuários do tipo bem misturado (Fig 5).

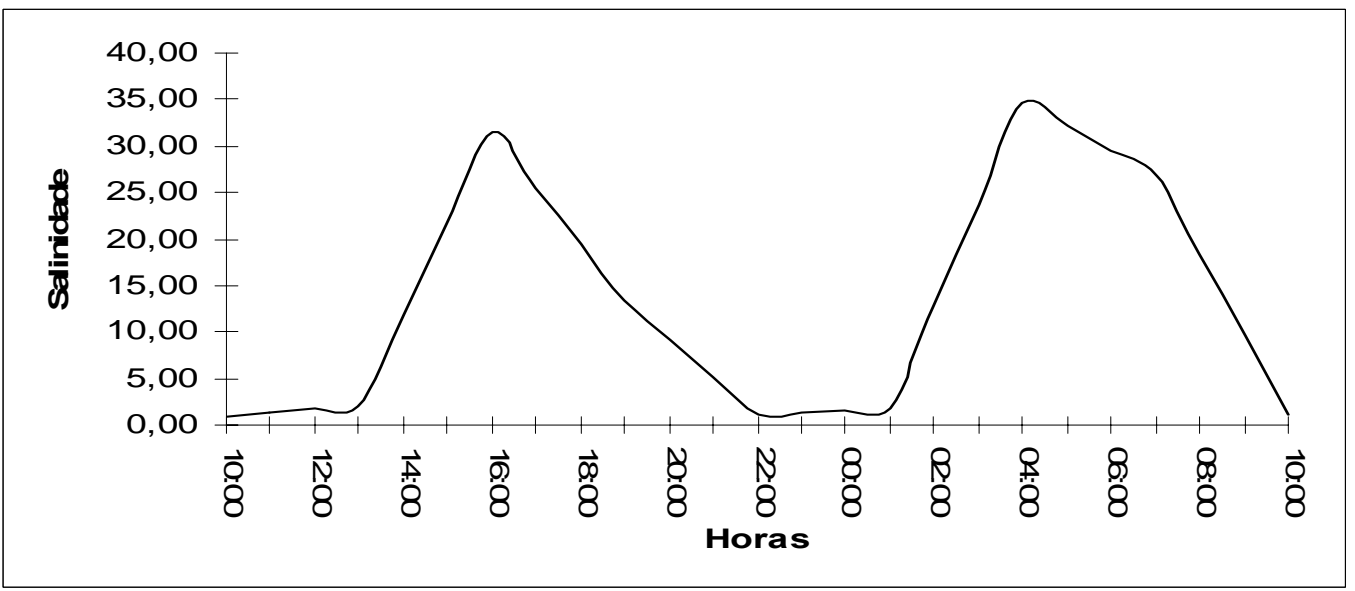

Figura 5 - Variação temporal da salinidade durante o período estudado no estuário de Barra das Jangadas.

\subsection{Fluxos}

Os fluxos dos nutrientes inorgânicos dissolvidos através da secção transversal na confluência do estuário da Barra das Jangadas, foram similares quando comparados com outros estuários brasileiros como o estuário do rio Camboriu-PR, e o sistema Mundau-Manguaba, AL,

Tropical Oceanography, Recife, v. 33, n. 2, p. 133-145, 2005. 
sistemas com altas concentrações de compostos principalmente nitrogenados. Estes fluxos apresentaram uma correlação direta com a descarga fluvial, evidenciando as características exportadoras do sistema.

Os altos fluxos registrados para a amônia (média: $25,33 \mathrm{~kg} \cdot \mathrm{h}^{-1}$, total: $608,00 \mathrm{~kg} \cdot \mathrm{d}^{-1}$ ), são evidências de um forte aporte de fontes antrópicas diretas e indiretas, influenciado pelo aumento na descarga fluvial neste período. Fato corroborado pelo aumento nas chuvas nos dias anteriores à coleta (normal neste período do ano). Estes fatores levariam a uma maior quantidade e menor qualidade dos lançamentos dos efluentes sem tratamento e, portanto, ricos em restos de produtos de limpeza amoniacais, e matéria orgânica que uma vez lançados na água se mineraliza, liberando uma alta taxa de amônia no meio. Os altos teores verificados nos estágios de baixa-mar e enchente, evidenciaram respectivamente o aporte por parte dos rios e a mistura no estágio seguinte. Apesar da concentração de nitrato também ser alta, os maiores aumentos foram observados na concentração de amônio, que entra nos rios carreado pelo esgoto urbano. É provável que esses altos teores sejam produto do baixo oxigênio dissolvido na área de estudo, fazendo com que não ocorra a oxidação do amônio para nitrato, provocando o acúmulo do primeiro no meio.

As concentrações registradas para a amônia (média:12,09 mm.m ${ }^{-3}$ )estão abaixo dos valores propostos pela legislação de $0,40 \mathrm{mg} . \mathrm{L}^{-1}$ (Resolução 357 do CONAMA, 2005) para corpos d'água classe 1 (salobres). Similar caso para o nitrato (média: $4,46 \mathrm{~mm} . \mathrm{m}^{-3}$ ) e nitrito (média: $0,72 \mathrm{~mm}^{-3}$ ) (0,40 e $0,07 \mathrm{mg} . \mathrm{L}^{-1}$, respectivamente).

Pereira-Filho et al.(2001), no estuário do rio Camboriú-PR, Brasil, observaram altas concentrações de amônia $(29,7 \mu \mathrm{M})$, determinando transportes de até $14,9 \mathrm{~kg} \cdot \mathrm{h}^{-1}$ na seção transversal estudada. Neste caso a seção de estudo possuía uma área um terço menor do que a área transversal de Barra de Jangadas e com velocidades menores das obtidas em nosso trabalho. Estes autores relataram que a forma predominante de NID (Nitrogênio Inorgânico Dissolvido) foi a amônia, apresentando elevadas concentrações.

Os teores de NID no presente trabalho, foram maiores que os registrados no estuário do rio Camboriú-PR, (Tab. 2), evidenciando que os compostos nitrogenados não foram limitantes para a produção fitoplanctônica.

O fosfato inorgânico dissolvido, embora presentes em pequenas concentrações, destaca-se como um dos principais constituintes reguladores no equilíbrio do ecossistema estuarino. A distribuição do fosfato verificada no tempo, evidenciou estes aportes principalmente durante a noite. Similar à amônia, ao nitrito e ao nitrato, os maiores teores foram registrados neste período onde a atividade fotossintética diminui e aumenta as quantidades deste nutriente no meio (Fig 6).

Tropical Oceanography, Recife, v. 33, n. 2, p. 133-145, 2005. 


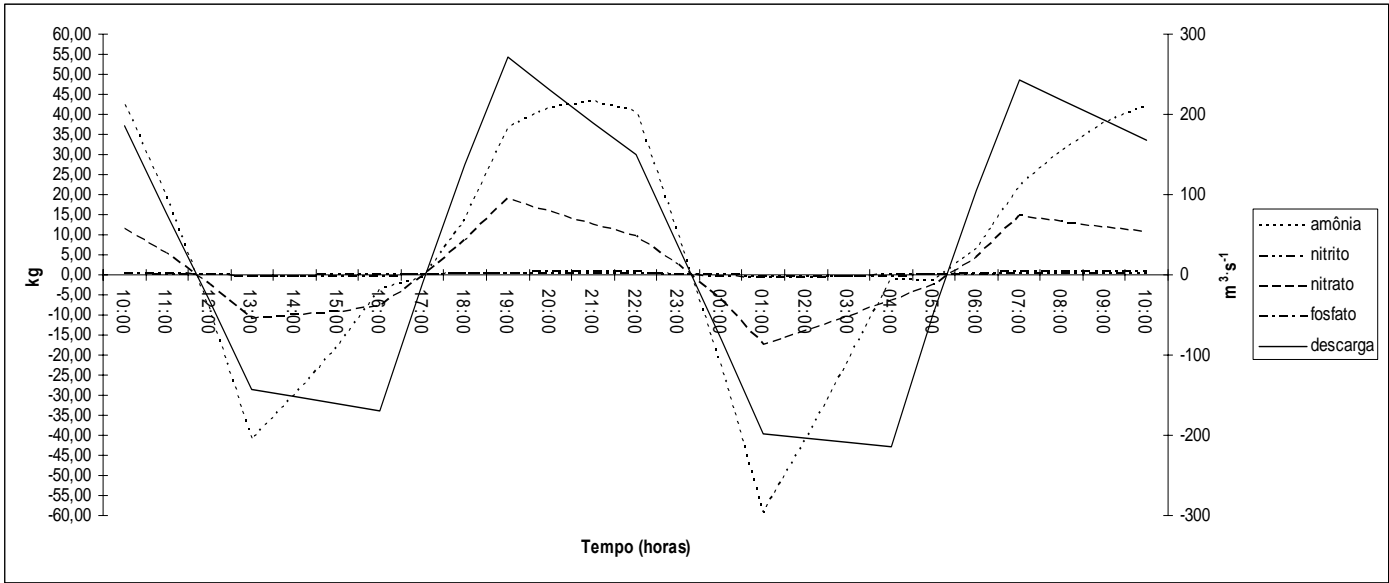

Figura 6 - Variação temporal dos fluxos médios $(\mathrm{kg})$ dos compostos nitrogenados e fosfatados em relação à vazão.

Durante o inverno e em estuários com elevada turbidez, como é o caso de Barra das Jangadas, onde a assimilação biológica é limitada pela disponibilidade da luz, outros fatores parecem ter o controle da biogeoquímica do fósforo. Segundo Mavellan (2003), é provável que as interações do fósforo com a matéria em suspensão, representem um mecanismo importante, sendo a fração particulada a que contenha uma maior quantidade este elemento. Apesar disso, o estuário apresentou uma característica típica, indicando ser influenciado pela atividade biológica, como é demonstrado no gráfico das diferenças do consumo entre o dia e a noite.

A concentração média obtida neste estudo $(0,96 \mu \mathrm{M}$; Tab. 2) é aproximadamente igual ao valor limite de $1,00 \mu \mathrm{M}$, sendo considerado um valor alto para a maioria dos estuários. Segundo Noriega et al. (2004), no referido estuário no ano de 2002, o valor máximo para o fosfato em uma maré baixa foi de $2,13 \mu \mathrm{M}$ nas estações interiores, sendo na zona de confluência registrada uma concentração e $0,94 \mu \mathrm{M}$, similar à registrada neste estudo.

As relações dos nutrientes propostas neste trabalho são as referidas por Redfield (1934) e Deggobis (1990), para N:P, de 16:1 e, Legovic et al. (1991).A relação N:P média (Relação de Redfield) para o período foi de 18:1, com maiores valores detectados durante o horário da manhã e início da tarde. Estes resultados evidenciam a atividade fotossintética, e o fosfato como elemento limitante. Taxas elevadas de N:P durante as marés com influência fluvial, foram verificadas próximas a 20:1, sendo compensadas com a entrada da água marinha estabilizando em seguida esta relação.

No caso da relação Si:P, é possível observar uma relação ainda maior (86:1), e para a relação $\mathrm{Si}: \mathrm{N}$, valores baixos de 4,8:1 foram detectados.

As conclusões tiradas neste trabalho indicando o fosfato como nutriente limitante, são baseadas nas estimações da relação N:P e Si:P do período, as diferenças das concentrações médias entre o dia e a noite (Fig. 3), e o grau em que o nitrogênio ou fosfato limitam a biomassa total do sistema em função das perdas no mesmo. Segundo Smith (1984), quanto mais fechado seja um sistema mais provável que seja limitado pelo fósforo.

As diferenças observadas nas concentrações médias entre o dia (06:00-18:00) e a noite (19:00-05:00) evidenciaram uma diminuição na absorção ou consumo por parte dos organismos autótrofos de $\Delta \%=10$ em relação ao fosfato (Fig 7). A pouca amplitude entre o dia e a noite para a

Tropical Oceanography, Recife, v. 33, n. 2, p. 133-145, 2005. 
salinidade, representa a pequena influência da evaporação no corpo de água $(\Delta \%=<3)$ neste período do ano.

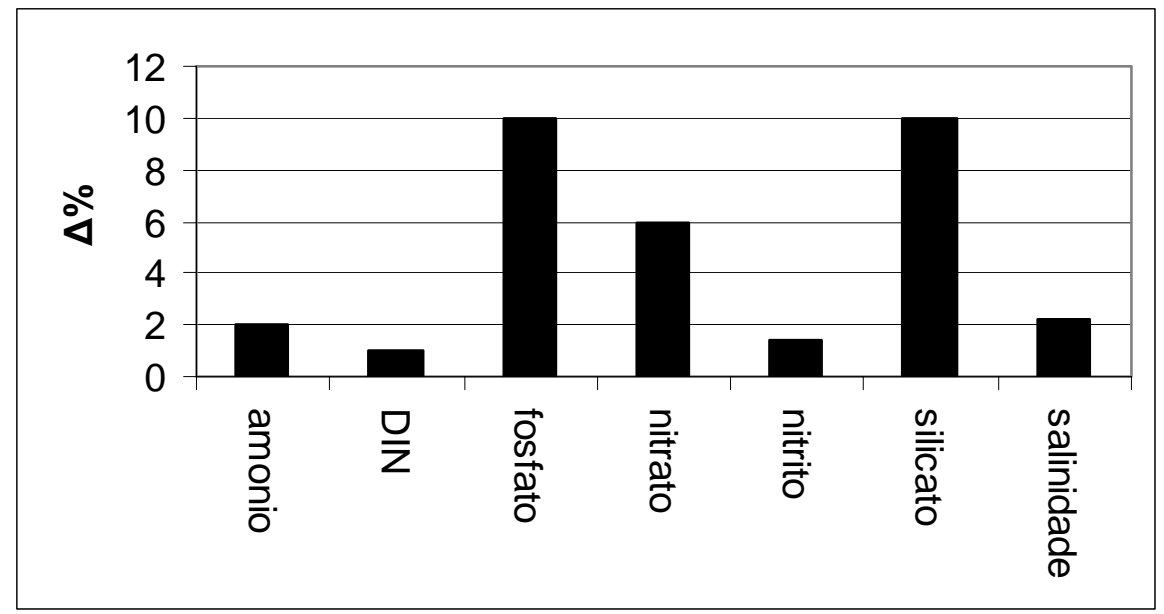

Figura 7 - Concentrações médias em relação à noite $(\Delta \%)$ de consumo de nutrientes.

O silicato é utilizado pelas microalgas do grupo das diatomáceas e dos silicoflagelados para formação das suas frústulas, sendo o nutriente inorgânico que se apresenta com as maiores concentrações nos ambientes estuarinos devido principalmente a sua origem terrígena. As concentrações de silicato foram altas no período estudado. Conseqüentemente os fluxos para a zona costeira chegaram a 770,00 kg.h ${ }^{-1}$ (média) e a $18.480,00 \mathrm{~kg}$ para os dois ciclos de marés (Tab. 2).

Segundo Meybeck (1982), o silício dissolvido, é um dos maiores constituintes das águas fluviais, perfazendo um total de $10 \%$ do total dos sólidos dissolvidos. A média global de acordo com este autor tem sido estimada em $80,83 \mu \mathrm{M}$, valor semelhante aos encontrados neste trabalho (Tab. 2).

Lacerda (2004), em seu estudo sobre a variação temporal da comunidade fitoplanctônica no estuário de Barra das Jangadas no ano 2001, relatou que as diatomáceas foram as principais representantes dessa comunidade tanto no período seco como o chuvoso, correspondendo a $44 \%$ do total dos grupos tetectados.

No presente trabalho, os altos teores registrados correspondem com os observados por Noriega et al. (2002) no estuário do rio Jaboatão. Segundo estes autores, o silicato apresenta uma expressiva remoção do ambiente, estando associada ao consumo pelo fitoplâncton, visto que, grande parte das microalgas em ambiente estuarino é composta por diatomáceas.

A distribuição temporal dos compostos estudados durante os ciclos de marés, apresentou altas concentrações de nutrientes inorgânicos dissolvidos nos períodos de baixa-mar e enchente, sendo estas reduzidas paulatinamente quando o estágio de preamar chegava a seu estofo, renovando a água, permitindo a oxidação gradativa da matéria orgânica, e dando à zona de mistura estuarina uma maior capacidade de depuração, que era mantida até a chegada do seguinte estágio de maré, onde a influência fluvial novamente se fazia sentir.

\section{CONCLUSÕES}


Os índices de amônia e silicato registrados no estuário de Barra das Jangadas, durante o período estudado, são resultados dos aportes antrópicos indiscriminados diretos e indiretos, através dos esgotos domésticos e industriais das cidades adjacentes, descarga fluvial, e lixiviação crescente neste período do ano, provocando uma deterioração na qualidade da água.

A forca das marés permitiu uma oxigenação temporal ao sistema durante o estágio de preamar, porém na enchente, baixa-mar e vazante, foram evidenciados os maiores fluxos e, conseqüentemente as piores condições na qualidade da água.

A relação N:P (18:1), sugere que o fosfato seja o elemento limitante à produção fitoplanctônica. Esta evidência é reforçada pelas diferenças de consumo entre o dia e a noite ( $10 \%)$.

A variação temporal dos parâmetros foi fortemente condicionada pela maré, verificando-se uma assimetria nas correntes de maré, com duração de $4,00 \mathrm{~h}$ para vazante e $6,30 \mathrm{~h}$ para enchente, em função de sua interação com os contornos do canal.

Os máximos valores de salinidade ocorreram com um quarto de período de diferença com os máximos valores de velocidade, que é comum para estuários do tipo bem misturado.

Faz-se necessário tomar medidas urgentes por parte das autoridades públicas, a fim de mitigar e controlar as descargas indiscriminadas de poluentes em ambos os rios (Pirapama e Jaboatão), caso contrário, as concentrações atuais aumentarão com a combinação de dois fatores (crescimento populacional e falta de esgoto tratado), provocando no sistema um empobrecimento maior na qualidade da água, afetando a distribuição de espécies e consequentemente a economia local, e turismo.

\section{REFERÊNCIAS BIBLIOGRÁFICAS}

BRASIL. MINISTÉRIO DO DESENVOLVIMENTO URBANO E MEIO AMBIENTE. Conselho Nacional do Meio Ambiente (CONAMA). 1986. Resolução n²0. Diário Oficial da União, 30 julho 1986, p.50-420.

CARNEIRO, O.; P. COELHO.1960. Estudo ecológico da Barra das Jangadas. Nota Prévia. Trab-s. Inst. Oceanogr. Univ. Federal de Pernambuco. Recife, 2(1):237-248.

CPRH - Companhia Pernambucana de Controle da Poluição e Recursos Hídricos. 2002. Planilhas de Controle industrial do Estado, UCOM/CPRH.

DHN. Tábuas das Marés. Recife - PE. 2003. Diretoria de Hidrografia e Navegação. Disponível em: http://www.dhn.mar.mil.br/chm/tabuas/30645jan2001.htm Acesso em 05 de agosto de 2003.

FALCÃO, J. P. 2002. Modelagem matemática da hidrodinâmica e da qualidade da água do trecho a jusante da Barragem do Rio Pirapama - PE, Brasil. Dissertação (Mestrado em Oceanografía Física), Universidade Federal de Pernambuco, Recife..

GRASSHOFF, K., M. EHRARDT, K. KREMELING. 1983. Methods of sea water analysis. 2 Ed. New York: Verlag Chemie. 317 p.

HANSEN V. D.; RATTRAY M. J. R. 1966. New dimensions in estuary classification. Limnol. Oceanogr., 11(3), 319-326.LACERDA, S. R. 2004. Série temporal do fitoplâncton no estuário de

Tropical Oceanography, Recife, v. 33, n. 2, p. 133-145, 2005. 
Barra das Jangadas (Jaboatão dos Guararapes - Pernambuco - Brasil). Tese (Doutorado em Oceanografia) - Universidade Federal de Pernambuc, Recife.

LINS, P. A. M. 2002. Hidrologia e hidrodinâmica do baixo estuário do Rio Ipojuca, Pernambuco. Dissertação (Mestrado em Oceanografia), Universidade Federal de Pernambuco, Recife.

MEYBECK, M. 1982. Cocentrations dês eaux fluviales em elemnts majeurs et apports em solution aux oceans. Rev. Geol. Dyn. Geogr. Phys. 21:215-246.

MIRANDA, L. B, B. M. CASTRO, B. M., B. KJERFVE. 2002. Princípios de Oceanografia Física de estuarios. São Paulo, S.P. Editora da Universidade de São Paulo. 424 p.

MOVELLÁN, E. 2003. Modelado de la cuña salina y del flujo de nutrientes en el tramo estuarino del rio Ebro. Tese de Doutorado, Universidad de Barcelona, Barcelona.

NORIEGA, C.E.D. 2004. Influência hidrológica e grau de poluição dos rios Pirapama e Jaboatão no estuário da Barra das Jangadas (PE-Brasil): Ciclo Temporal. Dissertação de Mestrado, Universidade Federal de Pernambuco, Recife.

NORIEGA, C.E.D.; COSTA, K. M. P. FEITOSA, F. A. N.; FLORES MNTES, M. J.; GREGO, C. K. S.; SOARES, G. S. S.; SILVA, H. P. 2004. Distribuição espacial da biomassa fitoplanctônica e sua relação com os sais nutrientes em um estuário tropical (Barra das Jangadas - PE - Brasil). Archivos de ciências do mar, 37: (no prelo)

PEREIRA-FILHO, J.; SCHETTINI, C.A.F.; RÖRIG, L.; SIEGLE, E. 2001. Intratidal variation and net transport of dissolved inorganic nutrients, POC and chlorophyll $a$ in the Camboriú River Estuary, Brazil. Estuarine, coastal and shelf science, 53:249-257.

SMITH, S.V. 1984. Phosphorus versus Nitrogen limitation in the marine environment. Limnology and Oceanography 29, 1149-1160.

SOUZA, A. D. G.; TUNDISI, J. G. 2003. Water quality in watershed of the Jaboatão river (Pernambuco, Brazil): a case study. Brazilian Archives of Biology and Technology, 46 (4):711-721.

STRICKLAND, J. D. H.; T. R. PARSONS. 1972. A Practical handbook of seawater analysis. 2 ed. Bulletin Fisheries Research Board of Canada, Ottawa, v. 167, p. 207-211. 
Tabela 1 - Altura (m) e fase relativa ao instante de preamar (PM) e baixa-mar (BM) no Porto do Recife e na estação de Barra das Jangadas.

\begin{tabular}{|c|c|c|c|c|c|c|c|c|}
\hline \multirow[b]{2}{*}{ Estação } & \multicolumn{4}{|c|}{$\begin{array}{l}\text { Dia } 29.07 .03 / \\
\text { Altura }\end{array}$} & \multicolumn{4}{|c|}{ Dia 30.07.03 / Altura } \\
\hline & Hora & $\begin{array}{l}\text { Barra das } \\
\text { Jangadas }\end{array}$ & Hora & $\begin{array}{l}\text { Porto } \\
\text { Recife }\end{array}$ & Hora & $\begin{array}{l}\text { Barra das } \\
\text { Jangadas }\end{array}$ & Hora & $\begin{array}{l}\text { Porto } \\
\text { Recife }\end{array}$ \\
\hline BM & $11: 25$ & 0,50 & $10: 38$ & 0,40 & & & & \\
\hline PM & $16: 40$ & 2,09 & $16: 41$ & 2,04 & $04: 55$ & 2,20 & $04: 56$ & 2,10 \\
\hline \multirow[t]{2}{*}{ BM } & $23: 25$ & 0,56 & $22: 43$ & 0,50 & & & & \\
\hline & \multicolumn{4}{|c|}{$\begin{array}{l}\text { Dia } 29.07 .03 / \\
\text { Altura }\end{array}$} & \multicolumn{4}{|c|}{ Dia 30.07.03 / Altura } \\
\hline Estação & Hora & $\begin{array}{l}\text { Barra das } \\
\text { Jangadas }\end{array}$ & Hora & $\begin{array}{l}\text { Porto } \\
\text { Recife }\end{array}$ & Hora & $\begin{array}{l}\text { Barra das } \\
\text { Jangadas }\end{array}$ & Hora & $\begin{array}{l}\text { Porto } \\
\text { Recife }\end{array}$ \\
\hline BM & $11: 25$ & 0,50 & $10: 38$ & 0,40 & & & & \\
\hline PM & $16: 40$ & 2,09 & $16: 41$ & 2,04 & $04: 55$ & 2,20 & $04: 56$ & 2,10 \\
\hline BM & $23: 25$ & 0,56 & $22: 43$ & 0,50 & & & & \\
\hline
\end{tabular}


Tabela 2 - Concentrações e fluxos relativos ao período de 2 ciclos de marés no estuário de Barra das Jangadas.

\begin{tabular}{|c|c|c|c|c|c|c|c|c|c|c|}
\hline Parâmetros & $\begin{array}{l}\text { Velocidade } \\
\left(\mathrm{m} \cdot \mathrm{s}^{-1}\right)\end{array}$ & $\begin{array}{l}\text { Área } \\
\left(\mathrm{m}^{2}\right)\end{array}$ & $\begin{array}{c}\text { Amônia } \\
\text { (mM) }\end{array}$ & $\begin{array}{l}\text { Nitrito } \\
(\mathrm{mM})\end{array}$ & $\begin{array}{c}\text { Nitrato } \\
\text { (mM) }\end{array}$ & $\begin{array}{c}\text { Fosfato } \\
\text { (mM) }\end{array}$ & $\begin{array}{c}\text { silicato } \\
(\mathrm{mM})\end{array}$ & $\begin{array}{l}\text { NID } \\
(\mathrm{mM})\end{array}$ & Salinidade & $\begin{array}{l}\text { Vazão } \\
\left(\mathrm{m}^{3} \cdot \mathrm{s}^{-1}\right)\end{array}$ \\
\hline Média & 0,2740 & 556,31 & 12,090 & 0,720 & 4,46 & 0,96 & 82,64 & 17,25 & 14,070 & 151,94 \\
\hline Máximo & 0,5040 & 616,60 & 21,418 & 1,140 & 6,32 & 1,84 & 129,24 & 28,88 & 34,719 & 270,72 \\
\hline Mínimo & 0,0604 & 530,00 & 0,306 & 0,206 & 2,16 & 0,44 & 22,91 & 2,67 & 0,976 & 9,44 \\
\hline Desvio padrão & 0,1300 & & 6,370 & 0,230 & 0,89 & 0,35 & 29,09 & 7,71 & 11,830 & 71,29 \\
\hline $\mathbf{N}$ & 175,0000 & & 175,000 & 175,000 & 175,00 & 175 & 175,00 & 175 & 175,000 & 175,00 \\
\hline Fmoles.h $^{-1}$ & & & 1809,300 & 110,980 & 682,00 & 145,01 & 12812,00 & 2602,40 & & \\
\hline Fkg.h $^{-1}$ & & & 25,330 & 1,550 & 9,55 & 4,50 & 770,00 & 36,43 & & \\
\hline Fmoles.2T & & & 43422,800 & 2774,600 & 16367,7 & 3480,30 & 307486,44 & 62456,70 & & \\
\hline Fkg.2T & & & 608,000 & 37,300 & 229,15 & 107,90 & 18480,00 & 874,40 & & \\
\hline
\end{tabular}

Tropical Oceanography, Recife, v. 33, n. 2, p. 133-145, 2005. 